\title{
Orbitozygomatic craniotomy in three pieces: tips and tricks
}

\author{
Craniotomia orbitozigomática em três peças: dicas e truques \\ Feres Chaddad-Neto1,2, Hugo Leonardo Doria-Netto ${ }^{1,2}$, José Maria Campos-Filho,,2, Mateus Reghin-Neto2, \\ Marcos Devanir Silva-Costa ${ }^{1}$ Evandro Oliveira ${ }^{2,3}$
}

\begin{abstract}
Objective: Didactically describe the orbitozygomatic craniotomy made in three pieces. Method: This approach was performed, from 2002 to 2011, in 49 patients admitted at Beneficência Portuguesa of São Paulo Hospital. Results: Twenty-seven patients had vascular lesions and twenty-two suffered for intracranial skull base tumors. The vascular lesions varied from cavernous angiomas inside the mesencephalum, high bifurcation basilar tip aneurysms, superior cerebellar arteries aneurysms and arteriovenous malformations in the interpeduncular cistern. Skull base tumors as meningiomas, interpeduncular hamartomas and third ventricle floor gliomas were among the neoplastic lesions approached. We had no permanent injuries and minimal transient complications had occurred. Conclusion: It is a descriptive text, organized in the sequence of the main stages in which such a craniotomy is performed, describing in details the technique in which this group of evolutionarily authors came to accomplish the task.
\end{abstract}

Keywords: orbitozygomatic, craniotomy, neurosurgery, microsurgery.

\section{RESUMO}

Objetivo: Descrever didaticamente a craniotomia orbitozigomática realizada em três peças. Método: Esse acesso foi realizado em 49 pacientes, de 2002 a 2011 em pacientes admitidos no Hospital Beneficência Portuguesa de São Paulo. Resultados: Vinte e sete pacientes apresentavam lesões vasculares e vinte e dois sofriam de tumores da base do crânio. As lesões vasculares variaram entre angiomas cavernosos do mesencéfalo, aneurismas topo da artéria basilar com bifurcações altas, aneurismas da artéria cerebelas superior a malformações arteriovenosas na cisterna interpeduncular. Tumores da base do crânio como meningeomas, hamartomas interpedunculares e gliomas no assoalho do terceiro ventrículo estão entre as lesões neoplásicas abordadas. Nós não tivemos sequelas definitivas e tivemos mínimas complicações temporárias. Conclusão: Trata-se de um texto descritivo, dividido conforme as principais etapas da realização desta craniotomia, o qual descreve com detalhes a técnica com que o presente grupo de autores evolutivamente veio a realizá-la.

Palavras-chave: orbitozigomática, craniotomia, neurocirurgia, microcirurgia.

The orbitozygomatic access was firstly described by Hakuba, in $1986^{1,2}$ as the result of small changes to the frontotemporosphenoidal craniotomy ${ }^{3,4,5}$.

Pterional craniotomy, popularized by Yasargil in 1976, is the most used surgical route in neurosurgery $\mathrm{y}^{6,7}$. It exposes transylvian and lateral subfrontal views ${ }^{8,9}$.

In 1961, Drake introduced the subtemporal approach ${ }^{10,11}$ which offers a lateral view of the interpenducular fossa by retracting the temporal lobe superiorly.

The temporopolar approach was firstly described by Sano in $1980^{12}$. It consists in pulling back the temporal pole, creating and enlarging an anterolateral view of the interpeduncular fossa.
The addition of transylvian and subfrontal views to the subtemporal and temporopolar views is of greatest importance when a neurosurgeon needs to expose the interpeduncular cistern region or the entire temporal lobe. The pretemporal approach, described by Oliveira et al. ${ }^{13,14}$, Tedeschi et al. ${ }^{15}$ and Chaddad Neto et al. ${ }^{16}$ combines the advantages of all these approaches in one craniotomy. This approach exposes the entire temporal lobe in order to offer the transylvian and lateral subfrontal views, from the pterional craniotomy, as well as subtemporal and temporopolar views to access the interpeduncular fossa.

The orbitozygomatic approach combines the advantages of the pterional and the pretemporal approaches but

\footnotetext{
'Universidade Federal de São Paulo (UNIFESP), Departamento de Neurologia, Sao Paulo SP, Brazil;

${ }^{2}$ Real e Benemérita Associação Portuguesa de Beneficência, Instituto de Ciências Neurológicas (ICNE), Laboratório de Microneurocirurgia, Sao Paulo SP, Brazil; ${ }^{3}$ Universidade Estadual de Campinas (UNICAMP), Faculdade de Ciências Médicas, Departamento de Neurologia, Campinas SP, Brazil.

Correspondence: Hugo Leonardo Doria-Netto; Al. dos Jurupis, 777 / apt 141; 04088-002 São Paulo SP, Brazil; E-mail: hldoria@hotmail.com

Conflict of interest: There is no conflict of interest to declare.

Received 19 May 2015; Received in final form 25 October 2015; Accepted 19 November 2015.
} 
improves the angle of microscope view from inferior to superior. Hence, it provides the best view for brain diseases at optic chiasm, third ventricle floor, high carotid artery bifurcation, high basilar tip artery bifurcation, anterior communicating artery aneurysms pointed posteriorly, and any other lesions at sellar and parasellar regions or interpeduncular region. This approach can even access the sphenoidal, frontal, and ethmoidal sinuses, the components of the orbit, the cavernous sinus and the remaining structures of the middle cranial fossa.

\section{METHOD}

Since 2002 to 2011 we have performed forty-nine (49) orbitozygomatic (three pieces) approaches to patients admitted at Beneficência Portuguesa of São Paulo Hospital.

Among these patients, 27 (55.1\%) had vascular lesions and twenty-two (44.9\%) suffered for intracranial skull base tumors.

The vascular lesions varied from cavernous angiomas (3-11.1\%) inside the mesencephalum, high basilar tip aneurysms (12-44.4\%), superior cerebellar arteries aneurysms (7-25.9\%) and to arteriovenous malformations placed at interpeduncular cistern (5-18.5\%).

The skull base tumors varied from olfactory groove meningiomas (6-27.2\%), petroclival meningiomas (5-22.7\%), proximal sphenoidal wing meningiomas (9-40.9\%), interpeduncular region hamartomas (1-4.54\%) and third ventricle floor gliomas (1-4.54\%).

The same surgical team operated all the patients.

\section{Description of orbitozygomatic craniotomy}

Positioning: he patient is placed supine. The head should be held by a three-pin skull fixation device (Mayfield or Sugita model). The ipsilateral pin should be set on the mastoid region, while the two contralateral pins should be on the contralateral superior temporal line, above the temporal muscle, that should not be transfixed ${ }^{17}$.
Head positioning comprises a sequence of four movements for: lifting, extention, rotation and torsion. Once lifting, the head is positioned at a level above the right atrium; extension and rotation depend on the condition being operated; and in torsion, the angle formed by the head, neck and shoulder should be higher, so as to offer the surgeon to be in a closer lateral position with respect to the surgical area, in order to become parallel to the Sylvian fissure. Most of times, intending to expose higher brain pathologies, we should position the head in more extension to provide inferior to superior microsurgical view ${ }^{18}$.

Care must be taken so that the jugular veins remain compression-free throughout surgery, to prevent delay of venous emptying, brain swelling, and increased bleeding in the operating field.

Trichotomy: Patient's hair should be combed with a brush used for hand scrubbing that has been soaked in detergent solution (chlorhexidine or polyvinylpyrrolidone iodine), so as to facilitate shaving, that should be performed up to $2 \mathrm{~cm}$ from the region of the surgical incision. Shaving just prior to surgery allows for better fixation of fields, reduction of infection risks, and better fixation of the bandage after surgery.

Marking, antisepsis and scalp incision: We should start at inferior edge of the zygomatic arch, anterior to the tragus, and extend to the hemi-pupillary contralateral line in the frontal region, behind the hairline. The marked area anterior to the tragus should not be too anterior, so as to prevent sectioning the superficial temporal artery and the frontal branch of the facial nerve located anteriorly to that artery (Figure 1).

The antisepsis should be carried out with alcoholic solution of polyvinylpyrrolidone-iodine or chlorhexidine.

Scalp incision should be performed and the use of bipolar coagulation helps to avoid bleeding. The placement of wet gauze and later traction of the scalp flap can spare the use of haemostatic clips and specific staples for this purpose $\mathrm{e}^{8,16,17,18}$.

Interfacial dissection, zygomatic osteotomy, section and displacement of the temporalis muscle: The interfacial dissection of the temporalis muscle, as originally described by Yasargil, is specifically intended to preserve the front temporal branch
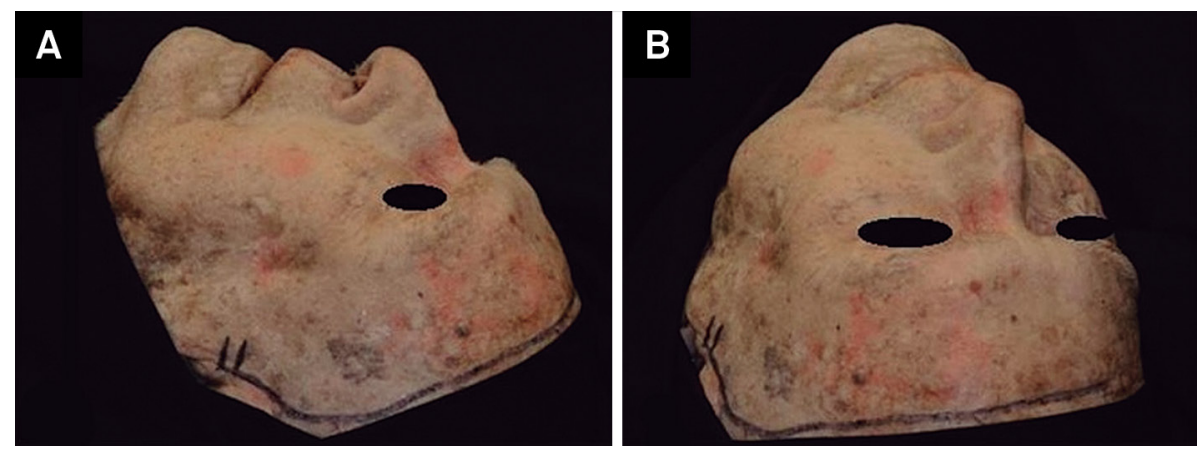

Figure 1. The skin incision starts $2 \mathrm{~cm}$ below the zygomatic arch anterior to the tragus (A), and extends to the hemi pupillary contralateral line in the frontal region (B). 
of the facial nerve and reduce postoperative cosmetic changes resulting from the surgical wound ${ }^{8,16}$. We had four patients $(8,1 \%)$ who evolved with temporary (about two months) frontal branch facial nerve palsy. None of them had permanent palsy.

The temporalis muscle is composed of two parts: an outer part which originates in the superior temporal line and inserts onto the coronoid process of the jaw-bone; and a deeper part that has its origin along the surface of the temporal squama and inserts onto the temporal crest of the jawbone. The temporalis muscle is covered by a superficial fascia, which, in turn, consists of two layers (the superficial and deep layers). These are separated in their anterior portion by a pad of adipose tissue, and by a deep fascia that is more attached to the skull and protects, both, its vasculature (anterior, intermediate and posterior deep temporal arteries, branches of the maxillary artery) and its innervations (temporal branches of the mandible branches of the trigeminal nerve).

Dissection of the superficial fascia should be performed vertically, starting from the superior temporal line, 1.5 to $2 \mathrm{~cm}$ posteriorly to the superior rim of the orbit to the posterior root of the zygomatic arch, with the aid of a \#10 scalpel. The removal of the surface layer of the superficial temporal fascia and its underlying fat pad with the use of a hook placed at its center point facilitates completion of the dissection, whose basal layer is hindered by the presence of temporal nerves and vessels. With the most basal removal of the surface layer and the fat pad, good visualization of the deep muscular portion is achieved. After the fascia is reflected anteriorly, the zygomatic bone with its frontal and temporal process is well exposed. The superior orbital rim and the supraorbital foramen and nerve are identified. The supraorbital nerve is freed within the orbit with great care not to injure the periorbita. The periorbita is usually thinnest and weakest at the exit point of the supraorbital nerve from the orbit and at the level of the frontozygomatic suture, which corresponds to the position of the lacrimal gland within the orbit (Figures 2 and 3).

After the zygomatic process of the temporal bone (zygomatic arch) and the zygomatic bone with its frontal and temporal process are well exposed, we perform the zygomatic osteotomy. The edge of the inferolateral temporal lobe corresponds externally to the upper edge of the zygomatic arch. From the lower dislocation of the zygomatic arch, it is possible to inferiorly move the temporal muscle facilitating optimal exposure of the floor of the middle fossa. Using the number 1 Penfield dissector, we can move the muscle and connective tissue adherent to the zygomatic arch. The osteotomy is performed to the zygomatic arch anteriorly to the temporal-zygomatic suture, in a vertical cut and posteriorly previously to the temporomandibular joint, in a oblique cut. It is important to preserve the insertion of the masseter muscle into the inferior edge of zygomatic arch which should be inferiorly dislocated.

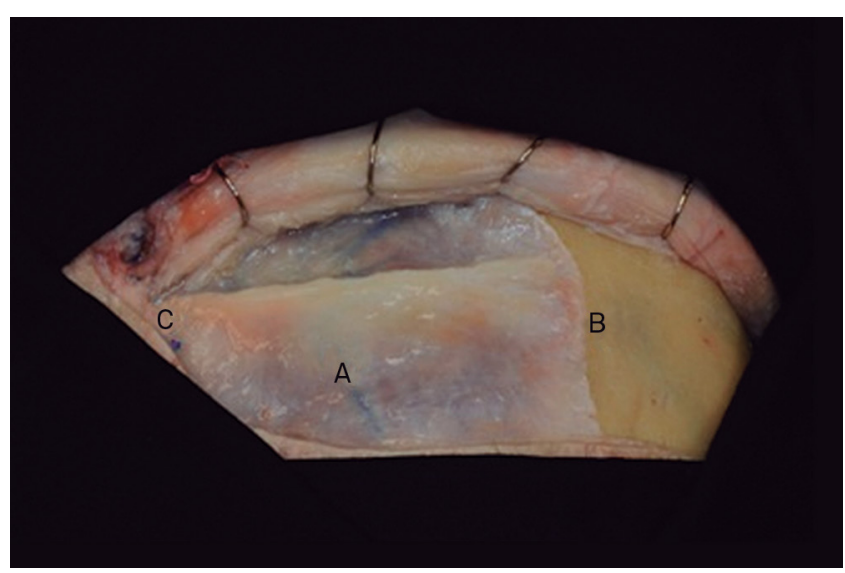

Figure 2. The interfacial dissection of the temporalis muscle. Dissection of the superficial fascia from the superior temporal line to the posterior root of the zygomatic arch. (A) temporalis muscle, (B) Superior temporal line, (C) Posterior root of zygomatic arch.

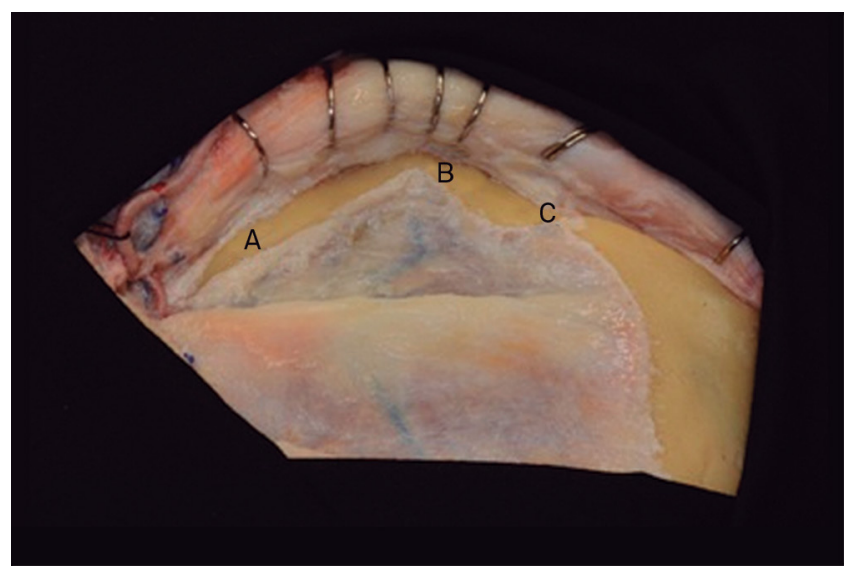

Figure 3. The zygomatic process of the temporal bone (A), the zygomatic bone with its temporal (B) and frontal process (C).

Afterwards the microsurgery, zygomatic arch must be reconstructed using mini-plates and screws or tied down with nylon at the edges (Figure 4).

The dissection and detachment of the temporalis muscle are then performed in two stages. Initially we use the monopolar electrosurgery pencil (in the coagulation mode intending to avoid bleeding) for the transversal section of the upper portion of the temporal muscle. The second stage consists of detaching of the deep muscular fascia of the skull. Afterwards, the temporal muscles must be moved away, towards the posterior inferior section, with the aid of three hooks. The insertion of the masseter muscle in the lower portion of the zygomatic arch is preserved when it is dislocated inferiorly toward the infratemporal fossa.

Craniotomy and orbital osteotomy: We perform a pretemporal craniotomy. The goal is to provide a basal and wide exposure of the temporal lobe and Sylvian fissure. We must expose the inferior frontal gyrus and a portion of the middle frontal gyrus, and the superior, middle and inferior temporal 

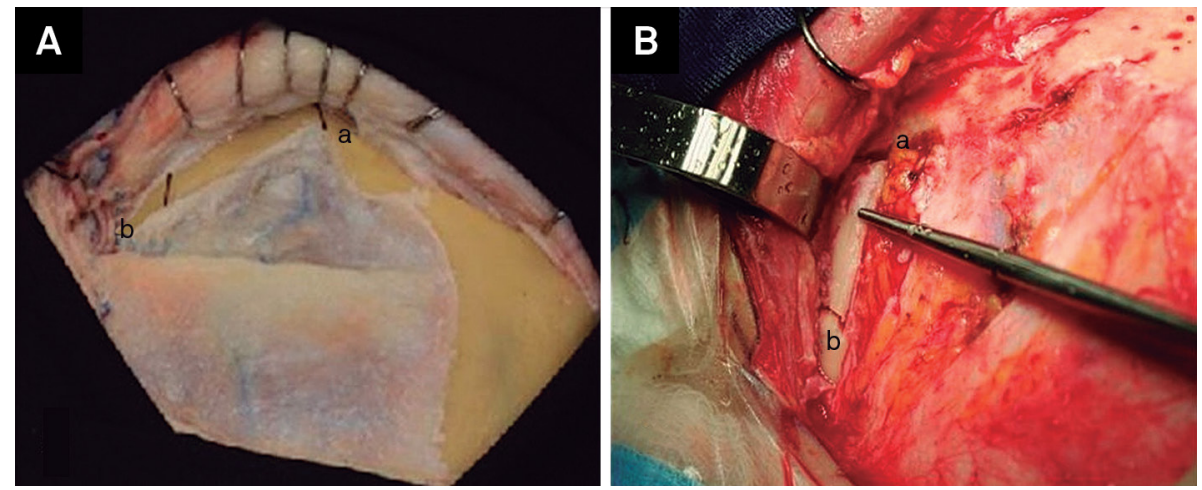

Figure 4. (A) The zygomatic osteotomy is done to the zygomatic arch anteriorly at the junction of the zygomatic arch with the temporal process of the zygomatic bone (a) and posteriorly previously to the temporomandibular joint (b). (B) Surgical view of the anterior (a) and posterior (b) zygomatic osteotomy.

gyri allowing for access through the transylvian, lateral subfrontal, temporopolar and subtemporal views.

The pretemporal craniotomy should be performed starting from three points of trepanation. The first trepanation must be set between the superior temporal line and the frontozygomatic suture of the external orbital process; the second trepanation is performed on the most posterior extension of the superior temporal line and the third one should be made on the most inferior portion of the squamous part of the temporal bone. Since the lesser wing of the sphenoid bone is situated internally between the first and third trepanations, and this bone rim will be properly removed through drilling, the third trepanation should not be performed very close to the base to facilitate the osteotomy between these two trepanations.

Craniotomy may be performed always making the cut at the level of the outer edge of each trepanation.

Dura mater must be anchored with 4.0 nylon through perforations made along the bone edge, seeking thereby, to prevent extradural collections (Figure 5).

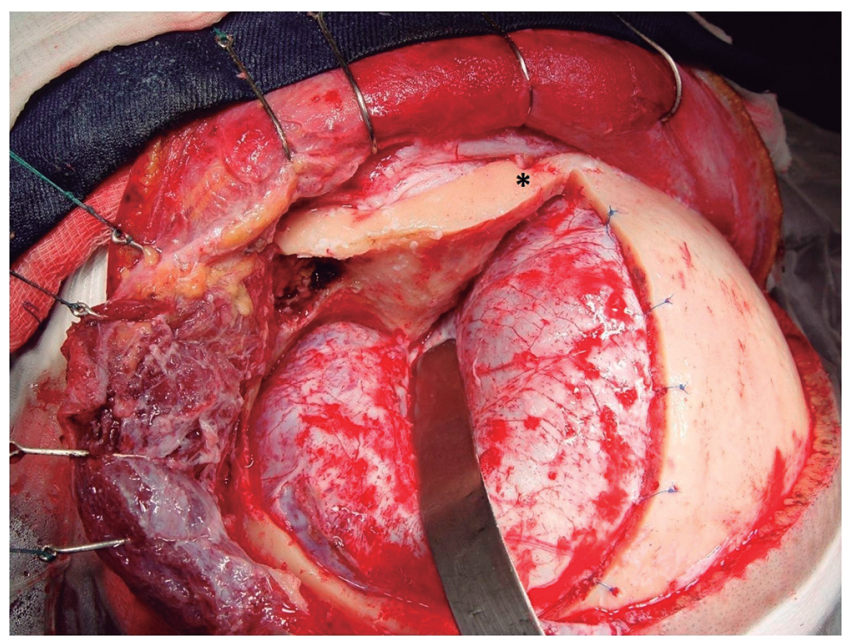

Figure 5. Surgical view of Pretemporal craniotomy, the orbital roof was flattened after drilling it. (*) Supraorbital foramen.
The purpose of drilling the lesser wing of the sphenoid bone, the orbital roof and what remains of the temporal squama is to achieve bone flattening to facilitate the basal access with minimal brain retraction.

Drilling should start on the outermost section of the orbital roof with the use of a cylindrical or round drill, seeking the removal of its bony prominences. Then, the base of the remaining temporal squama must be drilled so as to leave the lesser wing of the sphenoid projected between the orbital roof and the previously drilled temporal base. The lesser wing of the sphenoid bone should then be drilled following repositioning of the spatula on the dural impression of the sphenoid, until we obtain visibility of the dural fold that contains the meningo-orbital artery located at the superolateral level of the superior orbital fissure. Deeper to meningo-orbital dural fold the sphenoid lesser wing is considered to be the anterior clinoid process and it is not supposed to be drilled.

Drilling of the entire lateral surface of the larger wing of the sphenoid should be performed so as to expose the entire temporal pole, to achieve the temporopolar view. Drilling of the middle fossa floor to the foramen spinosum is done to expose the entire bottom surface of the temporal lobe to achieve the subtemporal route. Therefore, the drilling of the squamous temporal bone and greater wing of sphenoid bone should be performed until the floor of the middle cranial fossa is completely exposed, with complete release of the anterior and basal surfaces of the temporal lobe.

The most delicate drillings must be made with the use of match-shaped drills or diamond drills.

Orbital Osteotomy: The orbital osteotomy begins with the identification of the inferior orbital fissure at the inferior aspect of the lateral orbital wall. Then, we cut from the malar eminence to the inferior orbital fissure. Another cut extends through the roof of the orbit from the level or just lateral the supraorbital foramen to the superior orbital fissure, then, proceeds laterally to connect to the inferior orbital fissure. Removal of the orbital roof continues with 
bone rongeurs to the level of the planum sphenoidale medially, and laterally, the lateral orbital wall is removed until the dural fold in the most lateral aspect of the superior orbital fissure is well exposed. To aid the exposure, 4.0 nylon stitches are placed in the periorbita and after that, the orbit is retracted anteriorly.

There was not any enophtalmos among our patients (Figures 6, 7, 8 and 9).

Draping the operative field over the bony ridge: After positioning and arrangement of rectangular cotton blocks on the free bony ridge, blue drapes are placed on the pieces of cotton, aiming to cover the superficial cranial wraps and minimize the further reflection of light from the surgical microscope.

Opening the dura mater and brain exposure: The sectioning of the dura mater should be performed in such a way that, when folded back, the external dural surface adapts itself to the bone surface without forming wrinkles or folds that might obstruct the microneurosurgical field.

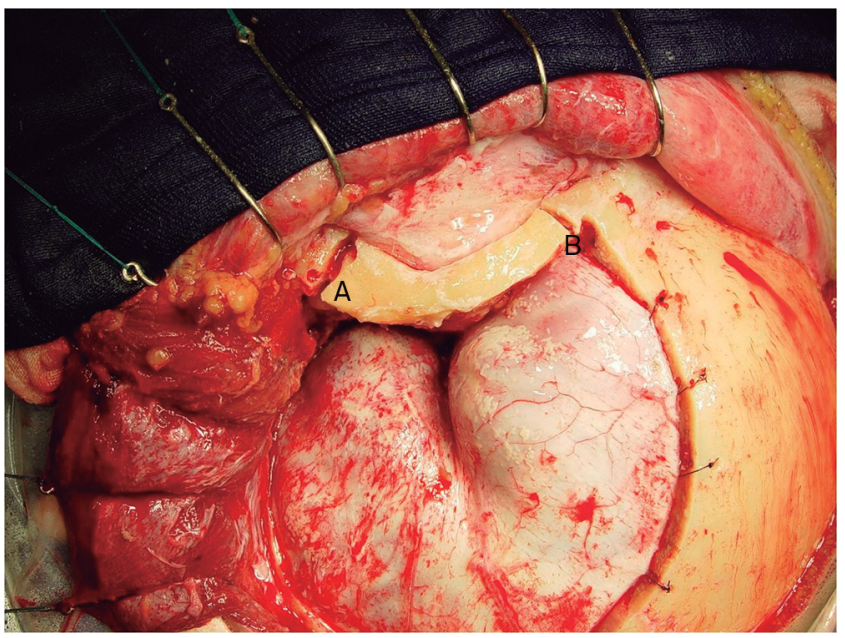

Figure 6. Orbital osteotomy from the malar eminence to the inferior orbital fissure (A) and from the level of the supraorbital foramen to the superior orbital fissure (B).

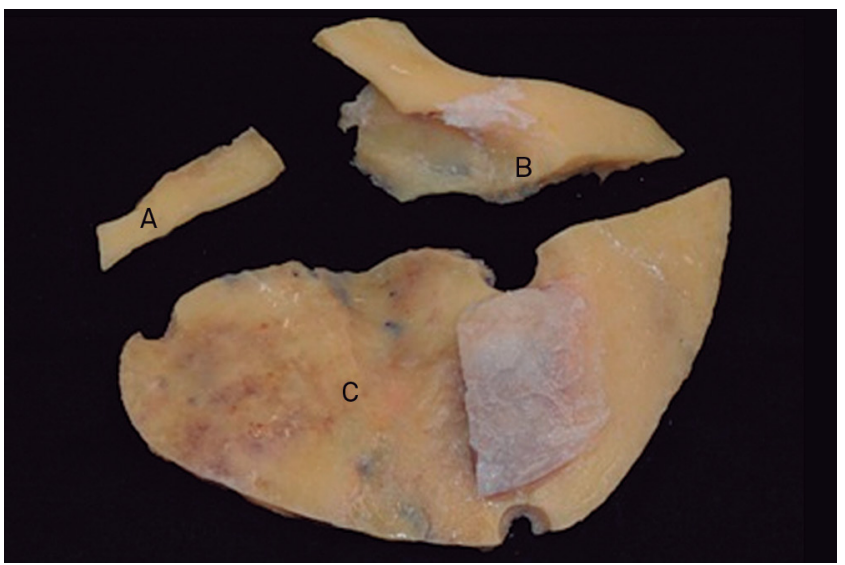

Figure 7. Three pieces of the Orbitozygomatic craniotomy: (A) zygomatic arch; (B) orbital roof; (C) Pretemporal osseous flap.
At the end of the dural opening, the shape should be of that of a large "S" so as to circumvent the temporal lobe, with the concave portion toward the rooftop free of orbit and the bottom toward the edge and bottom of the posterior craniotomy.

The dural incision should be initiated near the second trepanation, at the level of the most frontoparietal aspect of the dural exposure, using a scalpel blade \#11, and continued in the frontal superior direction, at this point with the use of Metzenbaum scissors. It then follows toward the Sylvian fissure, and then upward towards the superior orbital fissure and, finally, turns posteriorly, outlining the middle cranial fossa so as to fully expose the temporal lobe. The flap should be anchored with 4.0 nylon thread and pulled back in order to lift up the dural edges (Figure 10).

Opening of the Sylvian fissure: The Sylvian fissure is composed of a superficial and a deep part. The superficial part presents a stem and three branches; the stem extends medially from the semilunar gyrus of the uncus, between the basal

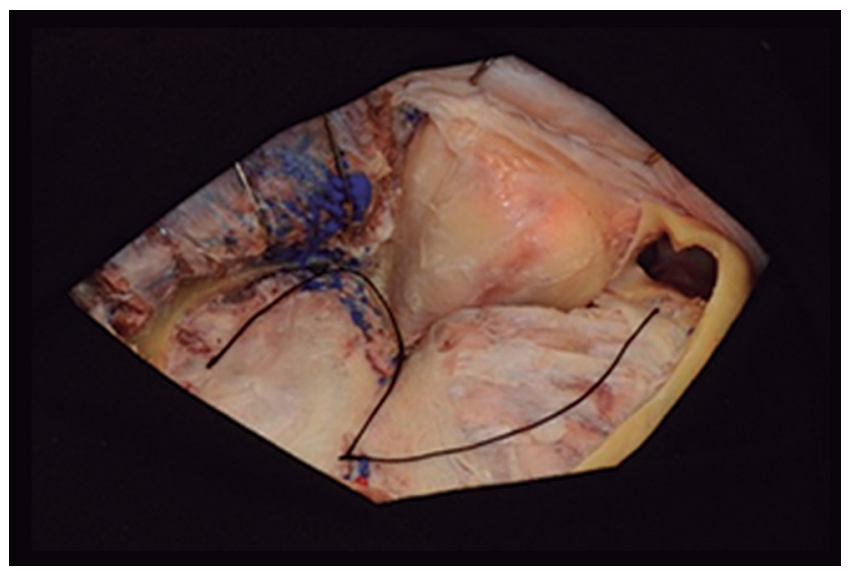

Figure 8. Cadaveric specimen showing the orbital osteotomy and the S shape dural open.

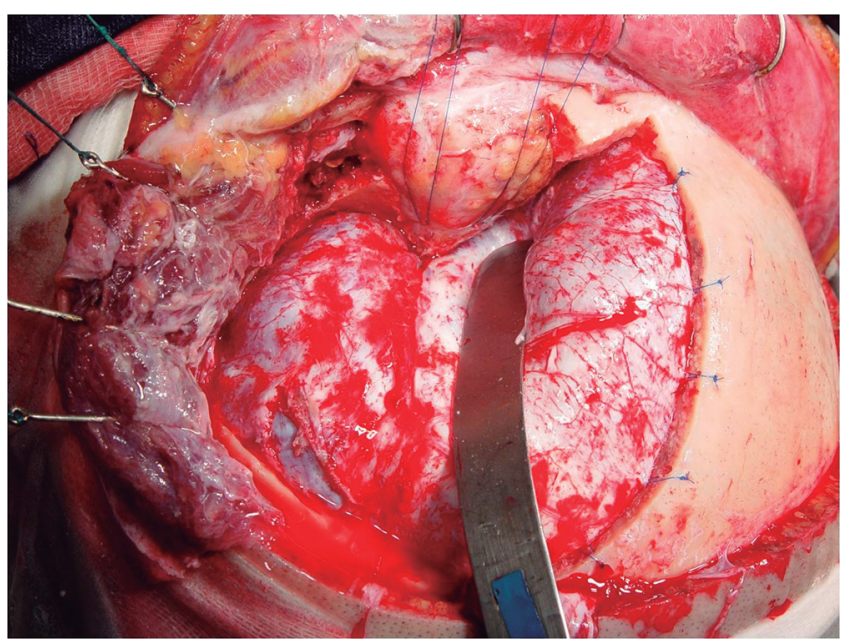

Figure 9. Surgical view of the Orbitozygomatic craniotomy, in order to aid the exposure, 4.0 nylon stitches are placed in the periorbita and the orbit is retracted anteriorly. 

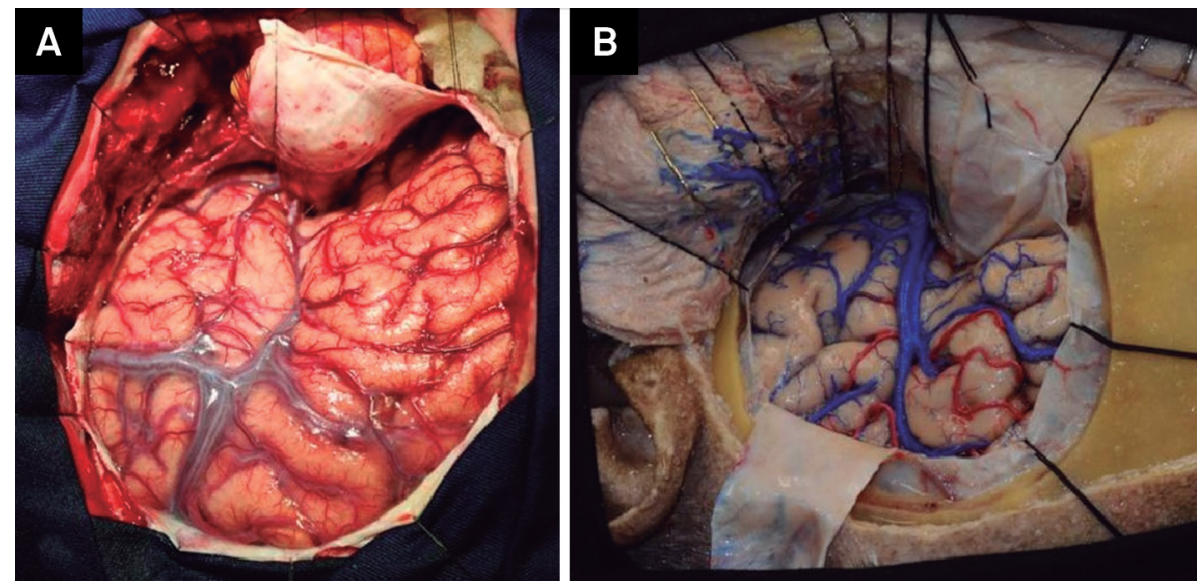

Figure 10. Surgical view (A) and cadaveric specimen (B) showing the dural opening and exposing the lateral fissure, the entire temporal lobe and the frontal lobe.

surface of the frontal lobe and the pole of the temporal lobe to the lateral end of the sphenoid ridge, where the stem divides itself into anterior horizontal, anterior ascending, and posterior branches. The deep part is divided in an anterior part, the sphenoidal compartment, and a posterior part, the operculoinsular compartment. The sphenoidal compartment arises in the region of the limen insulae, at the lateral margin of the anterior perforated substance. This compartment is a narrow space posterior to the sphenoid ridge, between the frontal and the temporal lobes, that communicates medially with the carotid cistern. The operculoinsular compartment is formed by two narrow clefts, the opercula cleft between the opposing lips of the frontoparietal and the temporal opercula and the insular cleft. The insular cleft has a superior limb located between the insula and the frontoparietal opercula and an inferior limb between the insula and the temporal operculum. The opercular cleft is composed of the frontal and parietal opercula superiorly and the temporal operculum inferiorly.

When the lips of the Sylvian fissure are widely separated we can see the insula. The insula connects the temporal lobe to the posterior orbital gyrus via the limen insulae. The limen insulae serves as a threshold between the carotid cistern (also called Sylvian vallecula) medially and the Sylvian fissure laterally. From microsurgical and radiologic viewpoints, the insula represents the external covering of a mass comprised of the extreme, external, and internal capsules, claustrum, basal ganglia, and thalamus ${ }^{19,20,21,22}$.

The orbitozygomatic approach proceeds with the opening of the Sylvian fissure and the basal cisterns. We usually open the basal cisterns before the Sylvian fissure to drain the cerebrospinal fluid, thus relaxing the brain, it makes the split of the Sylvian fissure easier. This splitting usually begins at the level of the pars triangularis, where the space between the frontal and the temporal lobes is wider.

The basal cisterns: Orbitozygomatic craniotomy enables the surgeon to reach the olfactory cistern, the carotid cistern, the chiasmatic cistern, the sphenoidal compartment of the Sylvian fissure, the cistern of lamina terminalis, the interpeduncular cistern, the ambient cistern and the crural cistern, which can be reached after the removal of the anteromedial segment of the uncus.

In order to accomplish the temporopolar approach to the interpeduncular cistern, the bridging veins draining the temporal pole to the sphenoparietal sinus and cavernous sinuses may be coagulated and cut when they would be binding temporal pole to middle fossa floor.

The arachnoid that binds the uncus to the oculomotor nerve and to the tentorial edge is opened, in order to achieve a nice mobility of the temporal lobe. By then, the temporal pole can be elevated superiorly through the subtemporal route and posteriorly through the temporopolar route.

The pretemporal orbitozygomatic allows the surgeon to deal with diseases arising from or extending to the anterior fossa, middle fossa, sellar and parasellar regions, interpeduncular region, petrous apex, and upper third of the clivus. The basal exposure of the anterior and middle cranial fossa also allows the treatment of the lesions that arise from or extend to the extra dural compartment of these regions. This approach can access the sphenoidal, frontal, and ethmoidal sinuses, the components of the orbit, the cavernous sinus, the infratemporal fossa, the petrous apex, the intrapetrous internal carotid artery and the remainder of the middle cranial fossa. This craniotomy allows an inferior to superior view of the microsurgical field, very useful in aneurysms of the anterior communicating segment with posterior projection occupying the interhemispheric fissure, in supra sellar lesions that project into the third ventricle and in high basilar bifurcation aneurysms.

It is of singular importance a suitable head extention in order to provide the best inferior to superior microsurgical view ${ }^{23}$.

The steps followed performing orbitozygomatic three pieces craniotomies have been facilitated dealing with forty-nine complex cases from 2002 to 2011. 
1. Hakuba A, Liu S, Nishimura S: The orbitozygomatic infratemporal approach. A new surgical technique. Surg Neurol. 1986;26(3):271-6. doi:10.1016/0090-3019(86)90161-8

2. Hakuba A, Tanaka K, Suzuki T, Nishimura S. A combined orbitozygomatic infratemporal epidural and subdural approach for lesions involving the entire cavernous sinus. J Neurosurg. 1989;71(5):699-704. doi:10.3171/jns.1989.71.5.0699

3. Al-Mefty 0 . The cranio-orbital zygomatic approach for intracranial lesions. Contemp Neurosurg. 1992;14(9):1-6. doi:10.1097/00029679-199214090-00001

4. Furth WR, Agur AM, Woolridge N, Cusimano MD. The orbitozygomatic approach. Neurosurgery. 2006;58(1 Suppl):ONS103-7. doi:10.1227/01.NEU.0000197050.70397.C1

5. Zabramski JM, Kiris T, Sankhla SK, Cabiol J, Spetzler RF. Orbitozygomatic craniotomy: technical note.J Neurosurg. 1998;89(2):336-41. doi:10.3171/jns.1998.89.2.0336

6. Yasargil MG, Antic J, Laciga R, Jain KK, Hodosh RM, Smith RD. Microsurgical pterional approach to aneurysms of the basilar bifurcation. Surg Neurol. 1976;6(2):83-91.

7. Yasargil MG, ed. Microneurosurgery. Stuttgart: Geor Thieme; 1984. Vol. 2, Basilar artery bifurcation aneurysms; p. 232-46.

8. Chaddad-Neto F, Campos Filho JM, Dória-Netto HL, Faria MH, Ribas GC, Oliveira E. The pterional craniotomy: tips and tricks. Arq Neuropsiquiatr. 2012;70(9):727-32. doi:10.1590/S0004-282X2012000900015

9. Chaddad-Neto F, Ribas GC, Oliveira E. [The pterional craniotomy step by step]. Arq Neuropsiquiatr. 2007;65(1):101-6. Portuguese. doi:10.1590/S0004-282X2007000100021

10. Drake CG. The surgical treatment of aneurysms of basilar artery. J Neurosurg. 1968;29(4):436-46. doi:10.3171/jns.1968.29.4.0436

11. Drake CG. The treatment of aneurysms of the posterior circulation. Clin Neurosurg. 1979;26:96-144.

12. Sano K. Temporo-polar approach to aneurysms of the basilar artery at and around the distal bifurcation: technical note. Neurol Res. 1980;2(3-4):361-7.
13. Oliveira E, Siqueira M, Tedeschi H, Peace DA. Surgical approaches for aneurysms of the basilar artery bifurcation. In: Matsushima T, editor. Cerebral aneurysms and skull base lesions. Fukuoka City: Sci Med; 1993. p. 34-42. (Matsushima T editor. Surgical anatomy for microneurosurgery; vol. 3).

14. Oliveira E, Tedeschi H, Siqueira MG, Peace DA. The pretemporal approach to the interpeduncular and petroclival regions. Acta Neurochir (Wien). 1995;136(3-4):204-11. doi:10.1007/BF01410627

15. Tedeschi H, Oliveira E, Wen HT. Pretemporal approach to basilar bifurcation aneurysms. Tech Neurosurg. 2000;6(3):191-9. doi:10.1097/00127927-200006030-00003

16. Chaddad-Neto F, Dória-Netto HL, Campos Filho JM, Ribas ESC, Ribas GC, Oliveira E. Head positioning for anterior circulation aneurysms microsurgery. Arq Neuropsiquiatr. 2014;72(11):832-40. doi:10.1590/0004-282X20140156

17. Chaddad-Neto F, Dória-Netto HL, Campos Filho JM, Reghin-Neto M, Rothon Junor AL, Oliveira E. The far-lateral craniotomy: tips and tricks. Arq Neuropsiquiatr. 2014;72(9):699-705. doi:10.1590/0004-282X20140130

18. Chaddad-Neto F, Dória-Netto HL, Campos-Filho JM, Reghin-Neto M, Oliveira E. Pretemporal craniotomy. Arq Neuropsiquiatr. 2014;72(2):145-51. doi:10.1590/0004-282X20130202

19. Ribas GC, Ribas EC, Rodrigues CJ. The anterior sylvian point and the suprasylvian operculum. Neurosurg Focus. 2005;18(6):1-6. doi:10.3171/foc.2005.18.6.15

20. Yasargil MG. Microneurosurgery. Stuttgart: Georg Thieme; 1984.

21. Yasargil MG, Krisht AF, Türe U, Al-Mefty O, Yasargil DCH. Microsurgery of insular gliomas: part I. Surgical anatomy of the Sylvian cistern. Contemp Neurosurg. 2002;24(11):1-8. doi:10.1097/00029679-200206010-00001

22. Yasargil MG, Krisht AF, Türe U, Al-Mefty O, Yasargil DCH. Microsurgery of insular gliomas: Part II. Opening of the sylvian fissure. Contemp Neurosurg. 2002;24(12):1-5. doi: 10.1097/00029679-200206150-00001 